\title{
The effect of infant feeding planning education on nutrition and breastfeeding knowledge, mother's attitude, and husband's support to expectant mother
}

\author{
Endah Wahyutri ${ }^{* 1}$, Jasmawati ${ }^{1}$, Kelana Kesuma Dharma ${ }^{2}$, Ratnawati ${ }^{1}$ \\ ${ }^{1}$ Health Polytechnic, MoH, East Borneo, Indonesia \\ ${ }^{2}$ Health Polytechnic, MoH, Pontianak, Indonesia
}

Received: July 16, 2017

Accepted: August 22, 2017

Online Published: September 15, 2017

DOI: $10.5430 /$ jnep.v8n1p87

URL: https://doi.org/10.5430/jnep.v8n1p87

\begin{abstract}
Background: The issue of malnutrition that leads to food security is not just a technical issue, but also a matter of individual habit to meet nutrients needed, including nutrients for fetus. The Government agrees to address the issue of food security in the first 1,000 days of life. This study aims at determining the influence of Infant Feeding Planning (Intention) Education on Nutrition and Breastfeeding Knowledge, Mother's Attitude, and Husband's Support to gravid Mother in Samarinda.

Methods: This study is a quasi-experimental research design with pre and post control group. The sample size was 30 in the intervention group and 30 in the control group. The independent variable in this study was intention to breastfeed, while the dependent variables were breastfeeding and nutrition knowledge, mother's attitude and husband's support. The data were analyzed using paired t test, Wilcoxon test, ANOVA and MANOVA.

Results: The study found the differences between intervention group and control group in nutrition knowledge, breastfeeding knowledge, and attitude. There was no difference between the groups in intention. The variables that influenced knowledge were education and employment. The variables influenced by the intention to breastfeed were breastfeeding knowledge, nutrition knowledge, and attitude. Intention had the greatest impact on the attitude, with the power observed at 0.689 which means that the intention affected the attitude of breastfeeding by $68.9 \%$.

Conclusions: Infant feeding planning education influences breastfeeding and nutrition knowledge as well as breastfeeding attitude.
\end{abstract}

Key Words: Nutrition knowledge, Breastfeeding, Attitude, Intention

\section{INTRODUCTION}

The issue of malnutrition that leads to food security is not just a technical issue, but also a matter of individual habit to meet nutrients needed, including nutrients for fetus. The Government and the World Food Program (WFP) agree to address the issue of food security in the first 1,000 days of life. Nutrition of the first 1,000 days of life is the nutrients given during 9 months or 270 days of pregnancy and in the first 2 years or 730 days of child growth. Lack of exclusive breastfeeding to babyaged 0-6 months is also one indicator of malnutrition in Indonesia. Indonesian mothers prefer to provide formula milk rather than exclusive breastfeeding due to their bustle as a career woman. This issue is also a concern for related parties as they have to lower the issue of malnutrition in Indonesia. ${ }^{[1]}$

The key targets of 2015-2019 Development Plan includes increasing Public Health and Nutrition Status, in which the

*Correspondence: Endah Wahyutri; Email: Wahyutriendah@yahoo.co.id; Address: Health Polytechnic, MoH, East Borneo, Indonesia. 
prevalence of underweight in toddler at $19.6 \%$ in 2013 decreased into $17 \%$ in 2019 and the prevalence of stunting (short and very short) in toddler under 2 years at $32.9 \%$ in 2013 decreased into $29 \%$ in 2019. In order to achieve these targets, the Ministry of Health introduced strategic plan to improve infant's health and quality of infant foods optimally in accordance with 1999 WHO's Innocenti Declaration. The strategic plan is included in the 2015-2019 Development Plan. Infant aged less than 6 months shall be exclusively breastfed $(50 \%)$ and newborn infant receives. Early Breastfeeding Initiation $(50 \%)$. The nine core messages of the first 1,000 days of life are: to have balanced nutrition during pregnancy, to have maternal checkup four times during pregnancy, to consume blood boosting supplements, to give Early Breastfeeding Initiation to newborn, to give exclusive breastfeeding for 6 months, to weighinfant monthly, to give basic and compulsory immunization to infant, to continue breastfeeding until the infant turns 2 y.o, to give complementary food gradually at age of 6 months and to continue breastfeeding.

The golden and critical period of child growth and development takes place in the first 1,000 days of life, meaning 270 days in the womb and 730 days during the first 2 years. The first 1,000 days of life is divided into several periods, namely: 280 days of pregnancy, 180 days when the baby aged 0-6 months, 60 days when the baby aged 6-8 month, 120 days when the baby aged 8-12 months, and 360 days when the baby aged 12-24 months. Those are 5 critical points of Indonesian child growth and development toward the "Qualified Generation". A child who is malnourished in the first 1,000 days of life is at risk of non-communicable or chronic diseases, depending on the affected organ. If the brain is affected, the child will have restriction in cognitive growth, making the child less intelligent and competitive. The child will have height growth disorder, making the child at risk of stunting.

Child nutritional status based on weight by age (W/A) index resulting in wasting tends to declineat the age of 3 months and continues to decline very rapidly until the age of 12 months and starts slowing down at age of 18-19 month. Meanwhile, based on weight by height $(\mathrm{W} / \mathrm{H})$ index resultingin stunting, the decline occurs at the age of 3 months to 15 months. An intervention conducted after the age of 2 years is not very effective because the child's condition have beenworse long before the child turns 2 years old. However, it does not mean that children aged 2 years and above are not a concern. This concept is about priorities. ${ }^{[2]}$

To increase the coverage of breastfeeding in order to prepare next generation, there are needs to design an effective- initiatives intervention which can encourgae the provision of peer-support for breatsfeeding mother. The breastfeeding program need an effort from all parties include: health support, family support, social network, workplace and work system, and government policy support.

This researh is an alternative provision of peer-support which are social support that integrated with Infant feeding planning in order to provide more knowledge. Mothers with breastfeeding knowledge will have a change of process (the Transtheoritical Model/TTM) ${ }^{[3]}$ Strengthen the mother's selfefficacy about breastfeeding ${ }^{[4]}$ and fostering intentions that will ultimately encourage mothers to make breastfeeding decisions

Theoretical framework used in this reasearch is Theory Of Planned Behavior (TPB). ${ }^{[5]}$

Appropriate counseling and education about breasstfeding practice can be adopted to achieve change of attitude, knowledge perception, and breastfeeding practice. Pregnancy care proved to be a good opportunity to improve breastfeeding knowledge. ${ }^{[6]}$

Peer support will be a process of sharing experiences and knowledge including: building mutual relationships, having great feelings, understanding stories, Sharing a way about stories that are not easy to understand, create a new story to solve the problems faced together. ${ }^{[7]}$

Husband's support is very necessary where proven that husband with lacks knowledge about breastfeeding; his baby was given bottle milks and is not ready to accept a new role to support breastfeeding6. Huband have an authority toward family decision including breastfeeding. ${ }^{[8]}$

Intervention conducted could be in the form of education and network of birth attendants in breastfeeding support group as an effort to increase breastfeeding intention andimprovenutritionknowledge, breastfeeding and positive intention regarding breastfeeding that will ultimately increase the coverage of Early Breastfeeding Intention and exclusive breastfeeding.

The statement of the problem of this study is whether there is influence of Infant Feeding Planning Education (Intention) on Nutrition and Breastfeeding Knowledge, Mother's Attitude and Husband's Support to Breastfeeding Support Group in Samarinda.

\section{MATERIALS AND METHODS}

This research is a Quasi Experiment Design with pre and post control group study. Research design in this research used Non-Equivalent Control Group: Compare intervention group with same control, where intervention group as well as 
control for participants. Eligibility criteria applied according inclusion criteria, first-born pregnant, never been attended breastfeeding and nutrition classes when ANC at Community Health Centers. Sampling was carried out using simple random sampling technique ${ }^{[9]}$ by using a random number generator program is research randomizer to determine the group.

Sample size 30 in the intervention group and 30 in the control groups with purposive sample technique.Paralel design formed with 30 mothers and 30 fathers in group comparison. Independent variable: Intent (Infant feeding planning) and dependent variables: Nutrition Knowledge and Breastfeeding, Attitude, Husband Support.

This research was conducted in Samarinda City, East Kalimantan Province by taking respondents from Air Putih Community Health Centers, Sempaja Community Health Centers, Pasundan Community Health Centers, Remaja Community Health Centers, Private Midwife Practice.

Where previously conducted Focus Group Discussion that attended from Community Health Centers, City Health Departement and Private Midwife Practice. At Focus Group Discussionshared regarding educational materials for peersupport breastfeeding module and the need for early breastfeeding Initiation. Data collection from May to July 2016.

The study on the intervention group was done by measuring pre test with breastfeeding and nutrition knowledge with education.Control groups was done by measuring pre test with breastfeeding and nutrition knowledge without education when they examined at Health Community Centers and Private Midwife Practices.Intervention and control groups conducted measurements with post test regarding intention on Infant feeding planning (breastfeeding, breastfeeding and formula milk, formula milk), attitude toward providing breastfeeding, Nutrition and breastfeeding knowledge, and husband support to provide breastfeeding, continued with nutrition education, breastfeeding and post test. The questionnaire has been tested for its validity with correlation formula "product moment person", all valid, and reability coefficition test showed realiabel if Cronbach alpha> 0,60. The result of realibility test with Cronbach alpha for nutrition knowledge 0,723 and attitude 0,795.

Before this research start, resepondentsare given an explanation about research courses, research objectives, benefits that obtained as respoendents research. If respondent agree, then they signed the informed consent.

This study has received ethical approval from the Ethics Committee in Research in Healthof Health Polytechnic Semarang number 75/KEPK/Poltekkes-Smg/EC/2016.

\section{RESEARCH RESULT}

In order to discover the effectiveness of the influence of Infant Feeding Planning Education (Intention) to Breastfeeding Support Group onNutrition and Breastfeeding Knowledge and Mother's Attitude parametric method Paired $T$ test was conducted to data which were normally distributed, as well as to datawhich were not normally distributed using Wilcoxon test.

To find out the effectiveness of Infant feeding planning (intention) with breastfeeding peer-support towards nutrition and breastfeeding knowledge, mother's attitude with differece analysis with parametrik method. The $T$-Test paired with normal distribution data, abnormal distribution data, with Wilcoxon Univariat analysis test.

Table 1 showed that on the characteristic of respondents regarding education, that the majority of education in both cases and controls is high school, on case $36.7 \%$ and control $46.7 \%$. The data of respondents for both case and Shapiro's control with normal distribution and Shapiro test Wilk $p$ value $.142>.005$, so the result of data become normal distribution.

The characteristic of respondents age for both case and control groups $20-35$ years specifically $86.6 \%$ on case and $80 \%$ on control, while age at risk $>35$ year for both case and control groups are same $6.7 \%$ and age $<20$ year for case $6.7 \%$ and control $13.3 \%$.

Furthermore, for both Shapiro's case and control respondent groups data with normal distribution and Shapiro Wilk Test $p$ value $.477>.005$ so data become normal distribution.

The characteristic of respondent occupation, majority for both case and control groups are housewife around 26 (86.7\%) and control 27 (90\%). The data of respondent for both Shapiro's case and control group with normal distribution and Shapiro Wilk Test $p$ value $.000<.05$ so data distribution become abnormal.

Table 2 indicates an increase mean value on nutritional knowledge in pre-cases 65 and post-test 75 and knowledge about breastfeeding pre-case 78.6 and post-test 90 , while at control case mean value nutrition knowledge pre-test 49.33 andpost test 59.66 knowledge about breastfeeding pre-test 71.33 and post-test 79.55. Distribution of data are normal with Shapiro Wilk $p<.05$ for case and control groups.

In Table 3 the result show that education that breastfeeding peer-support effectively increase nutrition knowledge $p$ value $.002<.005$, breastfeeding knowledge $p$ value $.001<.005$, Attitude $p$ value $.001<.005$. 
Table 1. The characteristic of respondents (education, age, occupation) case and control pregnant mother at Samarinda 2016

\begin{tabular}{|c|c|c|c|c|c|c|c|}
\hline \multirow{2}{*}{ Characteristic of Respondent } & \multicolumn{4}{|c|}{ Respondent's Group } & \multirow{2}{*}{ Total } & \multirow{2}{*}{$\%$} & \multirow{2}{*}{$p$} \\
\hline & Intervention & $\%$ & Control & $\%$ & & & \\
\hline \multicolumn{8}{|l|}{ Education: } \\
\hline Primary School & 5 & 16.7 & 4 & 13.3 & 9 & 15.0 & \multirow{6}{*}{.142} \\
\hline Secondary School & 7 & 23.3 & 3 & 10.0 & 10 & 16.7 & \\
\hline High School & 11 & 36.7 & 14 & 46.7 & 25 & 41.7 & \\
\hline Diploma & 2 & 6.7 & 3 & 10.0 & 5 & 8.3 & \\
\hline Undergraduate & 5 & 16.7 & 6 & 20.0 & 11 & 18.3 & \\
\hline Total & 30 & 100.0 & 30 & 100.0 & 60 & 100.0 & \\
\hline \multicolumn{8}{|l|}{ Age: } \\
\hline$<20$ & 2 & 6.7 & 4 & 13,3 & 6 & 10.0 & \multirow{4}{*}{.477} \\
\hline$>35$ & 2 & 6.7 & 2 & 6,7 & 4 & 6.7 & \\
\hline $20-35$ & 26 & 86.6 & 24 & 80,0 & 50 & 83.3 & \\
\hline Total & 30 & 100.0 & 30 & 100,0 & 60 & 100.0 & \\
\hline \multicolumn{8}{|l|}{ Occupation: } \\
\hline Housewife & 26 & 86.7 & 27 & 90.0 & 53 & 88.3 & \multirow{6}{*}{.000} \\
\hline Trader & 0 & 0.0 & 0 & 0.0 & 0 & 0.0 & \\
\hline Entrepreneur & 0 & 0.0 & 0 & 0.0 & 0 & 0.0 & \\
\hline Goverment Employees & 2 & 6.7 & 2 & 6.7 & 4 & 6.7 & \\
\hline Others & 2 & 6.7 & 1 & 3.3 & 3 & 5.0 & \\
\hline Total & 30 & 100.0 & 30 & 100.0 & 60 & 100.0 & \\
\hline
\end{tabular}

Table 2. The description of knowledge regarding nutrition and breastfeeding on Breastfeeding peer-support cases and controls 2016

\begin{tabular}{|c|c|c|c|c|c|c|c|c|c|}
\hline \multirow{2}{*}{ No. } & \multirow{2}{*}{ Variable } & \multicolumn{3}{|l|}{ Case } & \multirow{2}{*}{$p$} & \multicolumn{3}{|c|}{ Control } & \multirow{2}{*}{$p$} \\
\hline & & Mean & Min & Max & & Mean & Min & Max & \\
\hline 1 & Nutrition Knowledge Pre Test & 65 & 20 & 100 & .034 & 49.33 & 10 & 90 & .072 \\
\hline 2 & Breastfeeding knowledge Pre Test & 78.66 & 6.67 & 100 & .001 & 71.33 & 26.67 & 100 & .021 \\
\hline 3 & Nutrition Knowledge Post Test & 75 & 10 & 100 & .000 & 59.66 & 20.0 & 90 & .016 \\
\hline 4 & Breastfeeding knowledge Post Test & 90 & 53.33 & 100 & .000 & 79.55 & 33.33 & 100 & .012 \\
\hline
\end{tabular}

Table 3. Result Analysisof influence of education on breastfeeding peer support toward nutrition and breastfeeding knowledge, attitude on pregnant woman case and control groups in Samarinda 2016

\begin{tabular}{llllll}
\hline No & Variable & $\boldsymbol{p}$ Value Control & Statistic Test & $\boldsymbol{p}$ Value Case & Statistic Test \\
\hline 1 & $\begin{array}{l}\text { Nutrition knowledge } \\
\text { (Pre-Post) }\end{array}$ & 0.002 & Wilcoxon Test & 0.002 & Wilcoxon Test \\
2 & $\begin{array}{l}\text { Breastfeeding knowledge } \\
\text { (Pre-Post) }\end{array}$ & 0.004 & Wilcoxon Test & 0.001 & Wilcoxon Test \\
3 & Attitude & 0.041 & Paired T-Test & 0.001 & Paired T-Test \\
\hline
\end{tabular}

Table 4. Results of Analysis of the influence of infant feeding planning education on nutrition and breastfeeding knowledge, attitude, and husband's support to breastfeeding support group in Samarindain 2016

\begin{tabular}{lllll}
\hline No & Dependent Variable & Independent Variable & $\boldsymbol{p}$ & Statistical test \\
\hline 1 & Nutrition Knowledge & Infant feeding planning & .039 & Anova Kruskal-Wallis Test \\
2 & Breastfeeding Knowledge & Infant feeding planning & .045 & Anova Kruskal-Wallis Test \\
3 & Attitude & Infant feeding planning & .008 & Anova Kruskal-Wallis Test \\
4 & Husband's support & Infant feeding planning & .638 & Anova Kruskal-Wallis Test \\
\hline
\end{tabular}


The results of this research showed that there was influence of infant feeding planning education on Knowledge on $\mathrm{Nu}-$ trition and Breast Milkand Breastfeeding Attitude with $\mathrm{p}<$ .005 . However, the education did not influence husband's support with $p=.638>.005$.

Results of the analysis showed that the most influential variable on the intention to breastfeed was a positive attitude towards breastfeeding with $\mathrm{P}$ at 0.015 and Observed Power at 0.689 . Itindicates that the average value of attitudeto influence the intention to plan breast feeding is 68.9 times.

\section{Discussion}

Problems during the 730-day postpartum period are due to the lack of parents' knowledge on nutrition and nutritional attitudes resulting in poor quality of nutritional intake and parenting that will affect the child's nutritional status. This can be prevented if the mother has a good nutritional status, physical condition and health. Mother's nutrition knowledge affects the balance of nutrient intake which ultimately affects the growth and development of the child. Optimal nutrition fulfillment during 1,000-day postpartum period provides opportunities for the child to live longer, healthier, and more productive, as well as to have a lower risk for suffering from degenerative diseases. Child's growth in the golden period, during the first and second years, is rapid. However, in cases of malnutrition, the facts indicate that the decline in nutritional status occurs in this period. Therefore, food intake during pregnancy is essential to concern.

The study by Kim (2009) concluded that the knowledge on nutritionof expectant mother significantly affected some eating habits, in which the nutrition knowledge of expectant mother was positively correlated with good food habits and negatively correlated with poor eating habits. ${ }^{[10]}$

A study by Nuss et al. (2007) found that measuringknowledge in early postpartum measurement could identify the risk for future nutritional and health problems. Nutrition knowledge of woman who breastfeeds exclusively for more than six monthsis higher than the one of woman who breastfeeds for less than 6 months. ${ }^{[11]}$

This study is an alternative of social support integrated with the network of birth attendants and educationusing a module in order to improve knowledge. Knowledge or cognitive is anessential domain factor for the formation of one's behavior (Over Behavior). Based on experience and research, it turns out that knowledge-based behavior will be more lasting than behavior that is not based on knowledge, before one adopts new behaviors within a person. ${ }^{[12]}$

This study presents peers as breastfeeding support group, in

Published by Sciedu Press which women who had managed to breastfeed exclusively as a provider of social support would provide information, advice, and feedback on the conditions they had experienced so as to improve the knowledge of expectant mother on exclusive breastfeeding. ${ }^{[13]}$

According to Ferlander (2007), social support is generally positively related to health. However, asmall research has been conducted on how social capital or social networks affect health. ${ }^{[14]}$

A husband has the authority over family decisions, including breastfeeding8. Instructions on how to prevent and address breastfeeding difficulties given to husband is significant with the accomplishment of full duration of breastfeeding to 6 months. ${ }^{[15]}$ The role of a father in breastfeeding experience indicates the importance to support them by recognizing their unique contribution in parenting as member of lactation team. ${ }^{[16,17]}$ Encouragement to do their best, determination, and paternal commitment. ${ }^{[18]}$ Husband's decision on infant feeding, family protector. ${ }^{[19]}$

Counseling influences the knowledge of nursing motheron exclusive breastfeeding with $p$ value of .000 . The application of pocket book and simulation methods can effectively improve knowledge, making it easier for mothers to understand the material and information shared with peers when they have trouble. ${ }^{[20]}$

This study, in accordance with Lawton, Ashley, Dawson et al. (2012), encourages women to perceive breastfeeding as pleasant and comfortable. Conversation needs to focus on the positive and intentions from time to time. ${ }^{[21]}$

There are three factors that influence breastfeeding attitude, namely individual level, group level, and community level. ${ }^{[22]}$ Factor of individual level is directly related to the mother, the baby, and the mother-baby. Maternal factor includes knowledge, skills, parenting, experience status, maternal health that affects the risks of the mother and the baby, and early interaction between the mother and the baby. Each can directly affect initiation and duration of breastfeeding and is often correlated with social and demographic.

In this study,intention influenced the positive attitude to breastfeed. Specific concerns about breastfeeding and breastfeeding difficulties faced by the mother should be addressed by health workers in a more supportive manner. It is important to advocate public policy on working mother in the form of a breastfeeding supporting working environment to support working mother tokeep providing breastfeeding as well as to improve their intention and positive attitude to breastfeed. 
Research conducted through adopting the Theory of Planned Behavior (TPB) frameworkprovides a basis for understanding the practice of providing supplement. Implemented important information can be used to develop strategies to inform mothers and their families about the benefits as well as to support adherence to guidelines when recommend and introduce solid foods no earlier. ${ }^{[23]}$

TPB is said to be successful when applied to behaviors under individual's own control. If the behavior is not fully under individual's control or willingness, the individual may not show such behavior in real ${ }^{[24]}$ even though she is strongly motivated by her attitudes and subjective norms. Using the Theory of Planned Behavior approach conducted on lowincome nursing mothers. ${ }^{[25]}$ Kotan (2007) suggests that there is a correlation between knowledge, intention, parity, and perceived obstacles while breastfeeding.

According to Pettis (2010), using TPB approach, breastfeeding behavior takes practice and time to learn, resulting in a process of change in which the mother is convinced and willing to apply. ${ }^{[26]}$

Intention to breastfeed, according to Li et al. (2008), in postpartum period includes: exclusive breastfeeding, breast milk complementary food, no formula milk when the mother is not able to breastfeed due to working, eating nutritious food, and not on a diet during breastfeeding. ${ }^{[27]}$

The correlationbetween intention and behavior has been strongly proven, but some studies show their results are weak. There are several factors that influence the ability of intention in predicting behavior, such as specific and non-specific intentions, the time interval between measures of intention and behavior, and the ability to perform what has been said.

According to the concept of Theory of Planned Behavior (TPB), intention consists of three factors, namely attitude, subjective norm, and perceived behavioral control.

This study provides evidence that TPB can make a valuable contribution to understanding factors that predict differences in breastfeeding intention and initiation. A strong inten- tion to breastfeed at the end of pregnancy is interpreted into greater likelihood of breastfeeding initiation,given the support in the form of antenatal breastfeeding interventionthat will reinforce the strong motivation to breastfeed.

\section{Conclusion}

The Model of Integrated Breastfeeding Support Groups Network which presents birth attendant to breastfeeding support group consisting of expectant mothers and exclusive breastfeeding mothers with intervention in form of education on breastfeeding and nutrition is effective as it proved to have an influence on the improvement in breastfeeding and Nutrition Knowledge, positive attitude towards giving exclusive breastfeeding an positive attitude towards giving exclusive breastfeeding, with $93.3 \%$ intervention groups and $96.7 \%$ control groups with breastfeeding peer-support. The recommendation of this study is to conduct cohort research until the infant reaches 2-year-old to find out whether mothers who give exclusive breastfeeding continue breastfeeding for up to 2 years as the implementation of government program to prepare quality generations with the best food in 1000 first days of life.

\section{ACKNOWLEDGEMENTS}

We express our gratitude to the head of the Department of Health, Samarinda for granting us researchpermit, To the Head of Air Putih, Sempaja, Pasundan, and RemajaCommunity Health Centres for recommending expectant mothersto Ms.Erlina, Ms. EndangIriani, Ms. Hamdana, Ms. RatnaWati, Ms. Sri Pujiati, Ms. Murwati, Ms. Eni Marfuah, Ms. Yayuk, Ms. UsmiatiRahmah, Ms. Ratniah, and Ms. Fatimah Safaruddin who have been willing to be part of birth attendants networkfor breastfeeding support group, to expectant mothers as respondents of case and control groups, to Dr. Nina Mardiana and Dr. RahmatBahtiarof Faculty of Medicine, Mulawarman University, for the advice, and to all involved in the Focus Group Discussion and education class.

\section{CONFlicts OF INTEREST Disclosure}

The authors declare that there is no conflict of interest.

\section{REFERENCES}

[1] Bappenas. In Buletin 1000HPK. Bappenas. 2013.

[2] Shrimpton R, Kachondham Y. Analysing the Causes of Child Stunting in DPRK. Unicef. 2003.

[3] Prochaska JO. Systems of psychotherapy: a transtheoretical analysis. (Dorsey Press, 1979).

[4] Bandura A. Self-Efficacy: The Exercise of Control. Worth Publishers; 1997.
[5] Ajzen I. The theory of planned behavior. Organ. Behav. Hum. Decis. Process. 1991. https : //doi.org/10.1016/0749-5978(91 ) $90020-\mathrm{T}$

[6] Santo LC, de Oliveira LD, Giugliani ERJ. Factors Associated with Low Incidence of Exclusive Breastfeeding for the First 6 Months. Birth. 2007. PMid:17718871 https://doi.org/10.1111/j.15 23-536X. 2007.00173.x

[7] Jolly K, et al. Effect of a peer support service on breast-feeding con- 
tinuation in the UK: A randomised controlled trial. Midwifery. 2012. PMid:21944571 https://doi.org/10.1016/j.midw. 2011.08 .005

[8] Tan K. Factors associated with exclusive breastfeeding among infants under six months of age in peninsular malaysia. Int. Breastfeed. 2011. PMid:21284889 https://doi .org/10.1186/1746-4358-6-2

[9] Moher D, et al. CONSORT 2010 explanation and elaboration: Updated guidelines for reporting parallel group randomised trials. Int. J. Surg. 2012. PMid:22036893 https://doi.org/10.1016/j.ij su.2011.10.001

[10] Kim HW, et al. Development of the Pregnancy Nutrition Knowledge Scale and Its Relationship with Eating Habits in Pregnant Women visiting Community Health Center. J. Korean Acad. Nurs. 2009. PMid:19265310 https://doi.org/10.4040/jkan.2009.39.1 .33

[11] Nuss H, Freeland-Graves J, Clarke K, et al. Greater Nutrition Knowledge Is Associated with Lower 1-Year Postpartum Weight Retention in Low-Income Women. J. Am. Diet. Assoc. 2007. PMid:17904941 https://doi.org/10.1016/j.jada.2007.07.010

[12] Notoatmodjo S. Ilmu Perilaku Manusia. 2010.

[13] Wahyutri E. The Model Of The Effect Of Husband And Peer Support With Breastfeeding Education Class For Pregnant Women On Mother's Self Efficacy And The Process Towards Breastfeeding in Samarinda In 2013. Int. Ref. J. Eng. Sci. 2014.

[14] Ferlander S. The Importance of Different Forms of Social Capital for Health. Acta Sociol. 2007. https://doi.org/10.1177/000169 9307077654

[15] Pisacane A, Continisio GI, Aldinucci M, et al. A Controlled Trial of the Father's Role in Breastfeeding Promotion. Pediatrics. 2005. https://doi.org/10.1542/peds .2005-0479

[16] Rempel LA, Rempel JK. The Breastfeeding Team: The Role of Involved Fathers in the Breastfeeding Family. 2010. https ://doi or g/10.1177/0890334410390045

[17] Ramadani M, Hadi EN. Dukungan Suami dalam Pemberian ASI Eksklusif di Wilayah Kerja Puskesmas Air Tawar Kota Padang, Su- matera Barat. Kesmas Natl. Public Heal. 2010. https : //doi .org/ 10.21109/kesmas.v4i6.166

[18] Tohotoa J, et al. Dads make a difference: an exploratory study of paternal support for breastfeeding in Perth, Western Australia. Int. Breastfeed. 2009. PMid:19943958 https://doi.org/10.1186/ 1746-4358-4-15

[19] Februhartanty J, Muslimatun S, Septiari AM, et al. Fathers help to improve breastfeeding practice: can Indonesian fathers provide the same help? Universa Med. 2007.

[20] Merdhika WAR, Mardji M. Pengaruh penyuluhan asi eksklusif terhadap pengetahuan ibu tentang asi eksklusif dan sikap ibu menyusui di kecamatan kanigoro kabupaten blitar. Teknol. Dan Kejuru. 2014.

[21] Lawton R, Ashley L, Dawson S, et al. Employing an extended Theory of Planned Behaviour to predict breastfeeding intention, initiation, and maintenance in White British and South-Asian mothers living in Bradford. Br. J. Health Psychol. 2012. PMid:22950369 https://doi.org/10.1111/j.2044-8287.2012.02083.x

[22] Hector D, et al. Factors affecting breastfeeding practices. Applying a conceptual framework. N. S. W. Public Health Bull. 2005. PMid:16106273 https://doi.org/10.1071/NB05013

[23] Hamilton K, Daniels L, White KM, et al. Predicting mothers' decisions to introduce complementary feeding at 6 months. An investigation using an extended theory of planned behaviour. Appetite. 2011. PMid:21316413 https://doi.org/10.1016/j . appet.2011.0 2.002

[24] Ajzen I. Perceived Behavioral Control, Self-Efficacy, Locus of Control, and the Theory of Planned Behavior1. J. Appl. Soc. Psychol. 2002. https://doi.org/10.1111/j.1559-1816.2002.tb002 $36 . x$

[25] Kotan SE. Predictors of Breastfeeding Intention Among Low-Income Women. Florida State University. 2007.

[26] Pettis CT, Miller MK, Advisor D. A Theoretical Examination and Study of Breastfeeding Intensity and Duration. 2010.

[27] Li R, Fein SB, Chen J, et al. Why Mothers Stop Breastfeeding: Mothers' Self-reported Reasons for Stopping During the First Year. 2008. https://doi.org/10.1542/peds.2008-1315i 